\title{
Detection of Simulants of Chemical Warfare Agents on Textile Chemiresistors
}

\author{
A. Sýkorová ${ }^{1}$, E. Marešová ${ }^{1}$, D. Tomeček ${ }^{1}$, Š. Havlová ${ }^{1}$, P. Hozák ${ }^{1}$, J. Vlček ${ }^{1}$, L. Fišer ${ }^{1}$, P. Fitl', M. \\ Aleksanyan ${ }^{2}, A$. Sayunts ${ }^{2}, V$. Aroutiounian ${ }^{2}, M$. Vrňata $^{1}$ \\ *Dept. of Physics and Measurement, University of Chemistry and Technology Prague, Technická 3 , \\ CZ-166 28, Prague 6, Czech Republic \\ **Dept. Physics of Semiconductors and Microelectronics, Yerevan State University, 0025 Alek \\ Manoukian Str. 1, Yerevan, Republic of Armenia \\ Corresponding e-mail address: vrnatam@vscht.cz
}

\begin{abstract}
:
This contribution presents results of development of textile chemiresistors for detection of chemical warfare agents [1-2]. Such sensors are intended as parts of smart textiles. The bearing part of sensor is constituted from a woven non-conductive textile - and equipped with screen-printed graphite electrodes. The gas sensitive layer is composed of the polymeric ionic liquid based on Poly(Tributylhexyl phosphonium 3-sulfopropyl acrylate). Subsequently, responses of textile chemiresistors to $10 \mathrm{ppm}$ of four toxic gases or simulants of chemical warfare agents (methanol, nitrogen dioxide, diethyl malonate, 4-bromacetophenone) were measured in the dc-mode and acmode. The best achieved DC-response $S_{D C}=R_{\text {air }} / R_{\text {gas }}$ is $S_{D C}=1.8$ to $10 \mathrm{ppm}$ of 4-bromacetophenone. The results of AC-measurements are presented as Nyquist plots.
\end{abstract}

Key words: textile chemiresistors, polymeric ionic liquids, detection of simulants of chemical warfare agents

\section{Introduction}

The textile platforms, which are used as sensor substrates, are exhibiting beneficial large surface as well as the textile material is widely common and cheap. Some published results from last years show applicability of textile-based chemiresistors in the field of detection of chemical warfare agents [1-2].

Polymeric ion liquids (PILs), became very interesting substances for the gas sensing. Their properties as high electrical conductivity and their stability (chemical, thermal, mechanical) open-up new fields in detection of harmful and toxic gases and vapours - in these day mostly needed in security and public protection. Chemiresistors based on PILs can detect gas analytes as carbon dioxide with detection limits even in range of ppt [3].

\section{Experiments and results}

PIL based on Poly(Tributylhexyl phosphonium 3-sulfopropyl acrylate) was directly polymerized on textile substrates with previously printed carbon interdigitating electrodes. Scanning electron microscopy scans in fig. 3 reveal of structures on used woven and non-woven textiles. Sensors prepared by mentioned way were tested to detection of ppms of methanol, nitrogen dioxide, diethyl malonate, 4bromacetophenone in synthetic air. Pure synthetic air represents the reference atmosphere. Chemiresistors responses were recorded in $A C$ and DC regimes. Example of DC response to 4-bromacetophenon is shown in fig. 1 and Nyquist plot representing response to $10.6 \mathrm{ppm}$ of nitrogen dioxide is shown in fig. 2. The best achieved DC-response $\mathrm{S}_{\mathrm{DC}}=$ $R_{\text {air }} / R_{\text {gas }}$ is $S_{\mathrm{DC}}=1.8$ to $10 \mathrm{ppm}$ of 4 bromacetophenone. 


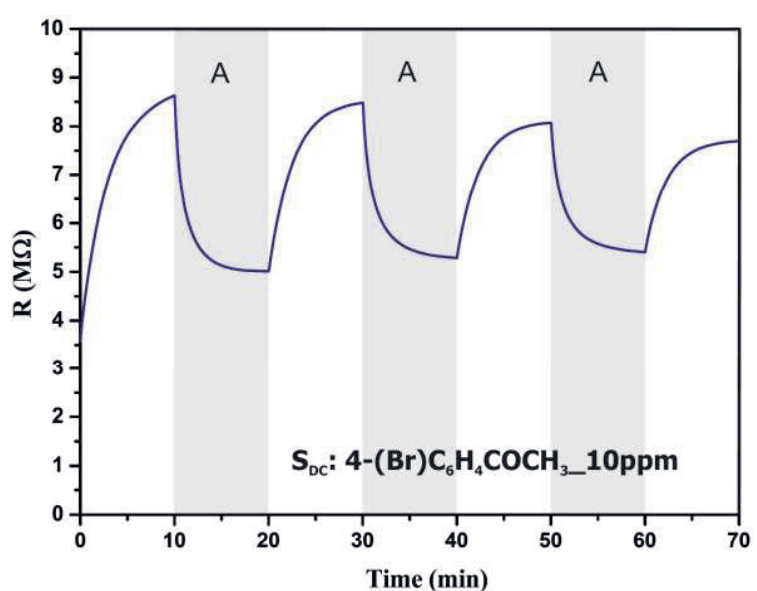

Fig. 1. DC chemiresistor response to $10 \mathrm{ppm}$ of 4 bromacetophenon.

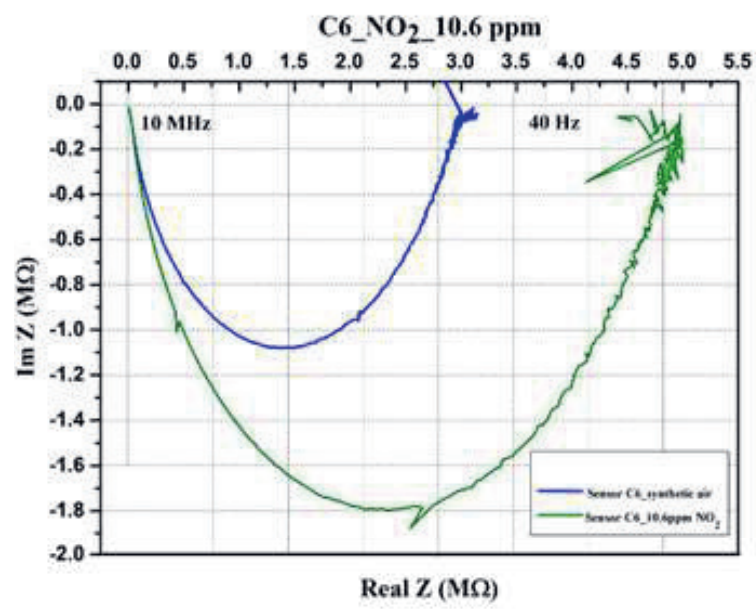

Fig.2. Nyquist plot of complex impedance of chemiresistor in synthetic air (blue) and in 10.6 ppm of nitrogen dioxide (green).

\section{Structure of textile substrates obtained by SEM}



Fig.3. Structures of textile sensor substrates: "global view" (a)-(c) and details (d)-(f).

\section{Acknowledgement}

This work was supported by NATO's Public Diplomacy Division in the framework of "Science for Peace" programme, project No.984597. Financial support from a specific university research (MSMT No 20-SVV/2016) is also acknowledged. One of the authors (Eva Marešová) is grateful to the Vakuum Praha company for funding her junior research project called "Vacuum sublimation of organic semiconductors and their utilization in gas sensors".

\section{References}

[1] T. Kinkeldei, C. Zysset, Sensors and Actuators B 174, 81-86 (2012); doi: 10.1016/j.snb.2012.08.023

[2] L. Caprineri, Procedia Engineering 87, 724-727 (2014); doi: 10.1016/j.proeng.2014.11.748

[3] R. Guterman, M. Ambrogi, J. Yuan, Macromolecular Rapid Communications 37 (14), 1106-1115 (2016); doi: 10.1002/marc.201600172 